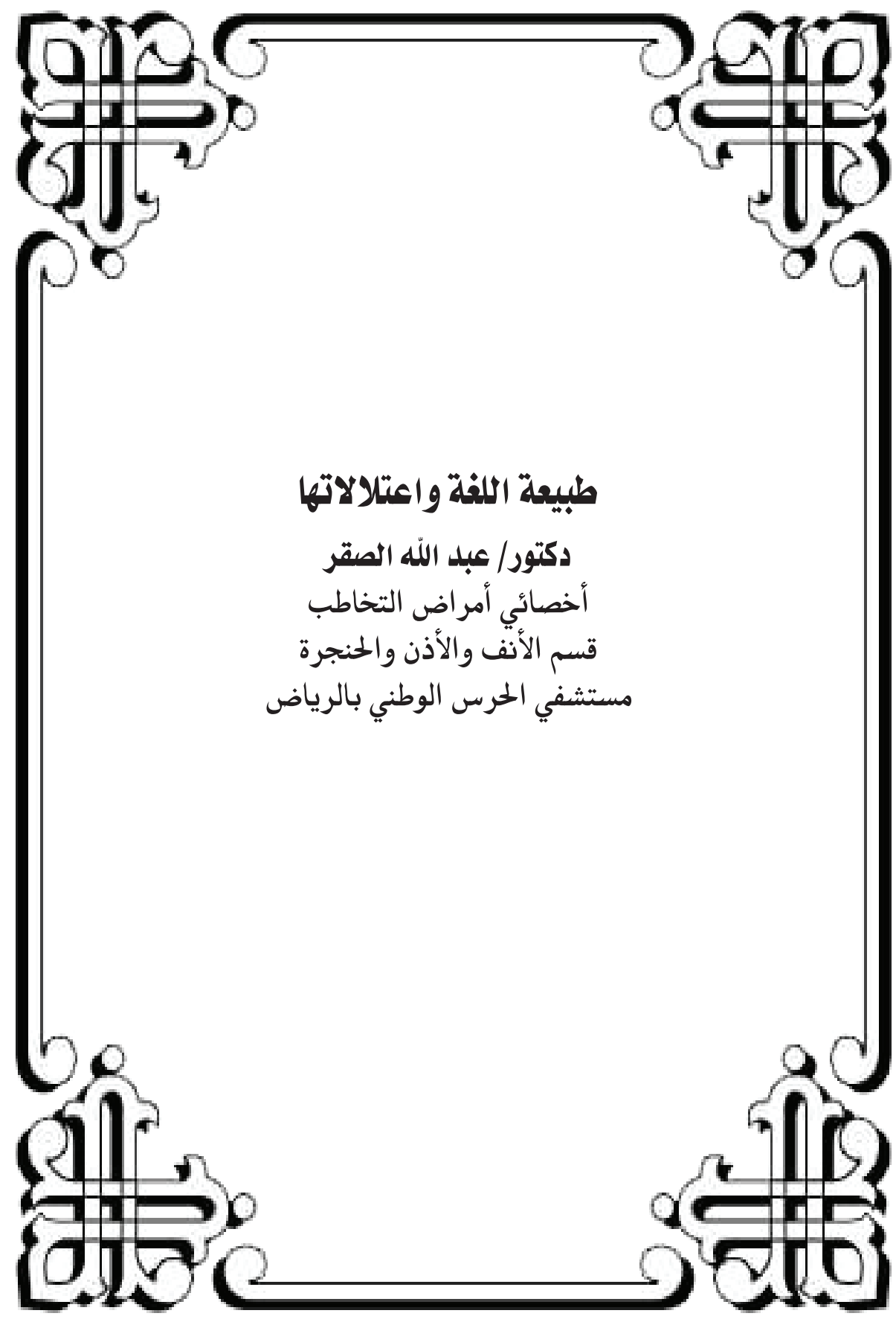





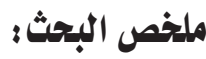

يتألف المقال من معلومات أساسـية يِّ مواضـيع مترابطة مناسبـة لتوضـيح

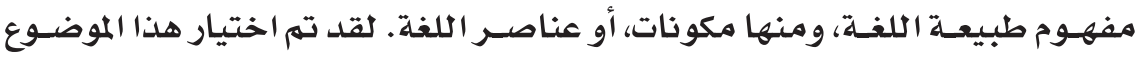

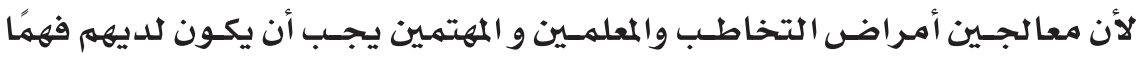

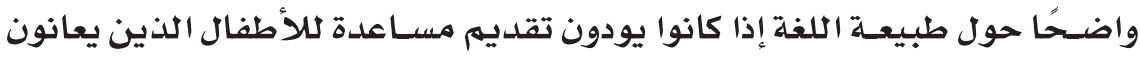

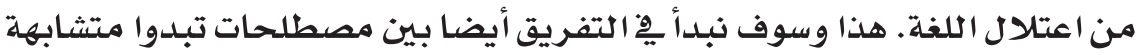

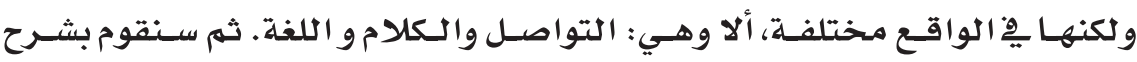

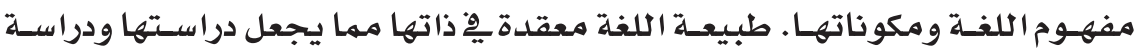

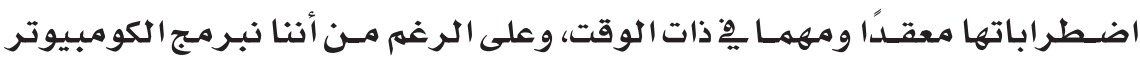

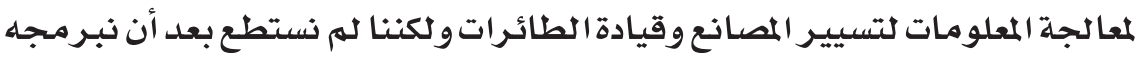

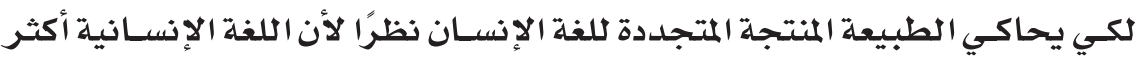

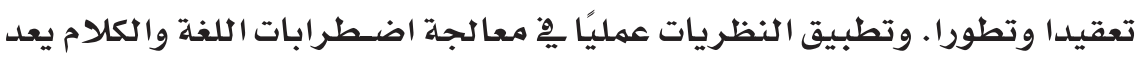

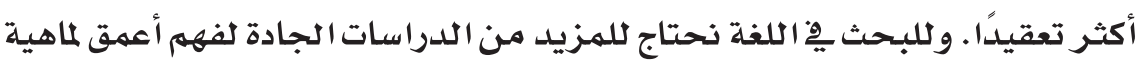

اللغة وطبيعتها واعتلا لاتها. الكلمات المفتاحية: طبيعة اللغة - اعتلالات اللغة. 


\section{language comorbidity}

The article consists of basic information in appropriate interrelated subjects to clarify the concept of language nature, such as language components or elements. This subject has been chosen as speech therapists and teachers interested must have a clear understanding about language nature if they would like to provide assistance for children who suffer from language comorbidity. Thus we will begin to differentiate between similar terms with a different reality namely: communication, speech and language. Then we will explain the concept of language and its components. Language nature is complex in itself, making its study and disorders complex and important at the same time, and although we are trying to use computer to process information for factories working and driving aircraft, we have not been able yet to make use of computer so that mimics nature producing renewable language because human language is more complex and sophisticated. applying theories in practically in treating speech and language problems is more complicated. looking at language we in gross need to more serious studies for a deeper understanding of its essence, nature and comorbidity.

Keywords: language - language comorbidity 


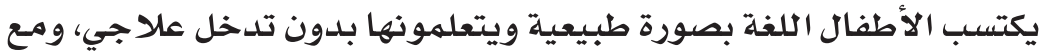

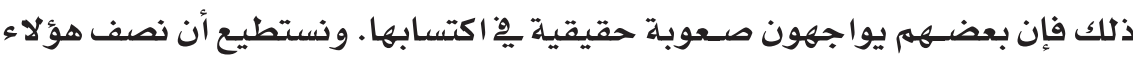

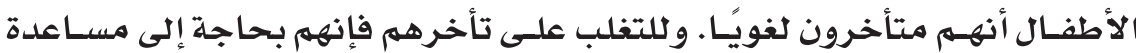

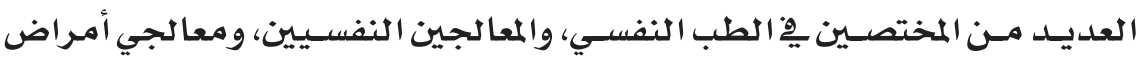

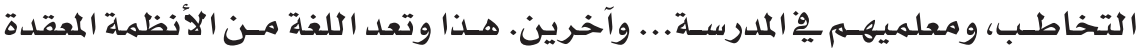

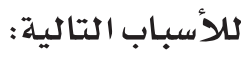

تعـدد قواعـد دراسـة تأخــر اللغة؛ مثـل: علـم أمـراضل التخاطب، والتربية

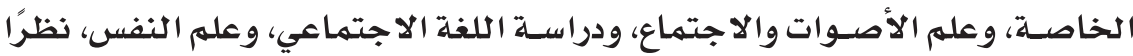

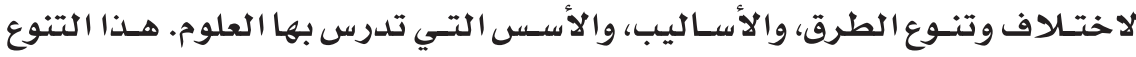

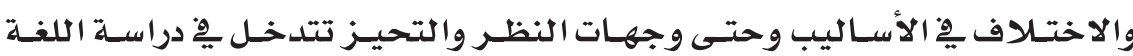
واضطراباتها.

طبيعـة اللغــة معقــدة هِّ ذاتها؛ مما يجعل دراسـة اضـطراباتها معقدًا، وعلى

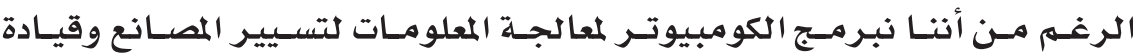

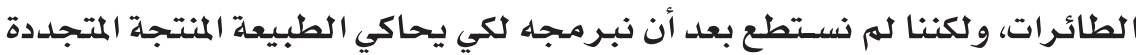

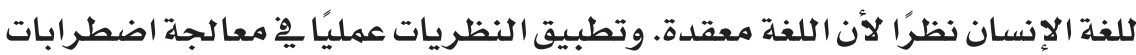
اللغة والكلام يعد أكثر تعقيدًا.

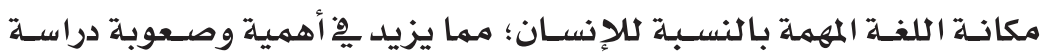

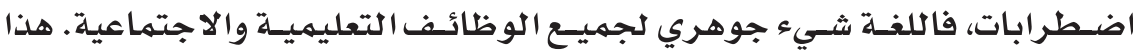

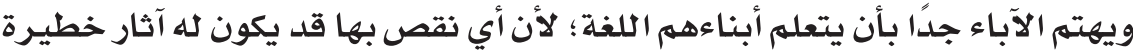

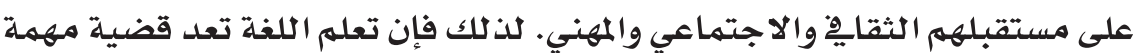
يِْ الثقافة وبقية الحقول الإنسانية.

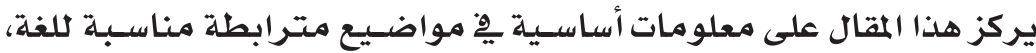

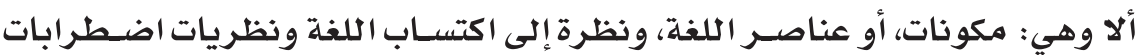

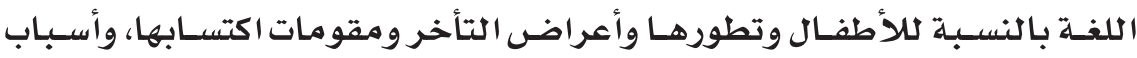

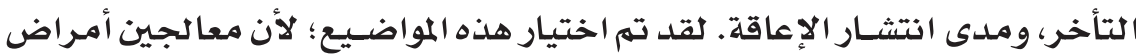


التخاطـب، والمعلمـين، والمهتمــين يجـب أن يكـون لديهم فهمًا واضسحًا حسول طبيعة اللغـة، وكيف يتم اكتسـابها إذا كانوا يودون تقديهم مسـاعدة للأطفال الذين يعانون من اعتلال اللغة.

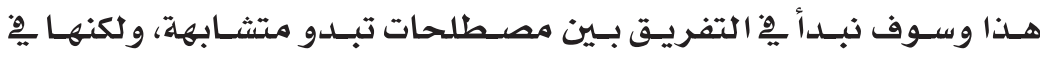
الواقع مختتلفة، ألا وهي: التواصـل والكلام، واللغة. ثم سـنقوم بشـرح مفهوم اللغة ومكوناتها.

\section{تعريـف التواصل و الكلام و اللغة:

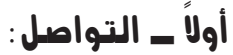

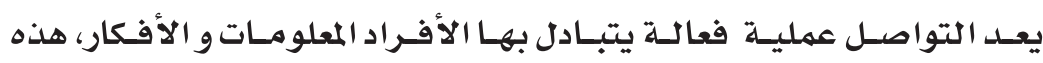

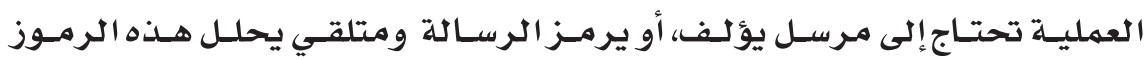

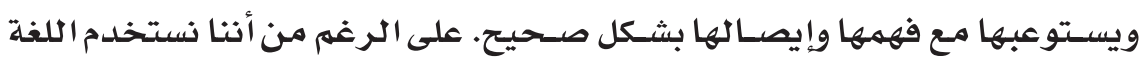
والكلام للتواصـل فإن طرقًا أخرى من التواصـل قد تعزز، أو تشـوه الرموز اللغوية

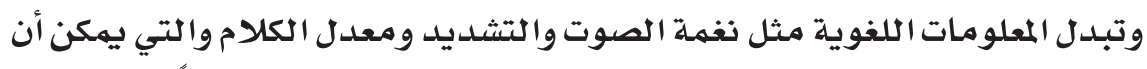
تشير إلى عواطف المتكله. بالإضـافة إلى هذه الطرق اللغوية يوجد طرقا غير لغوية

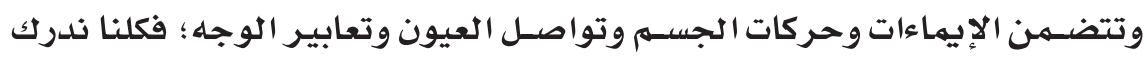

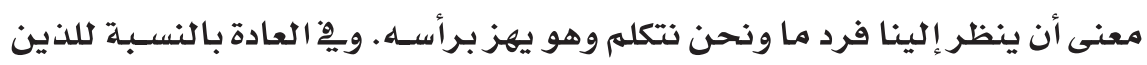
يتكلمون بلدون تواصل بصري فإنهم يفقدون الاهتمام بالتوا صل.

ثانيًا : الكلام

يعد الكلام أحد الوسائل الذي يتهم بواسطته نفل المعلومة شفهيًا، وهو يرتبط

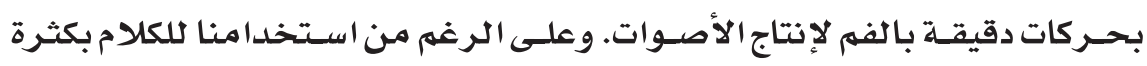
من أجل التواصل إلا أنه ليس الطريقة الوحيدة، بل توجد وسائل أخرى مثل الرسمى

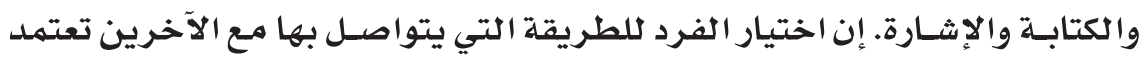
على سياق الموضوع و احتياجاته واحتياجات المتلقي و الرسالة التي يرغب بإرسالها.

بالنسـبـة لبعض الأطفـال المتأخرين يِّن اللغـة والكلام فإن اكتسـابهم للكلام ليس مهكنًا، ومع ذلك فإن العديد منههم يهكنهم اكتساب القدرة على التواصل إذا تم

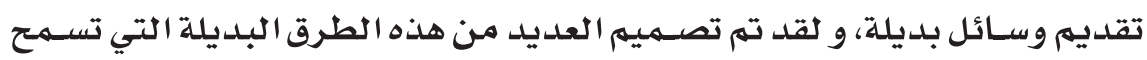
للأطفال بإرسال رسائلهم دون اللجوء إلى الكلام. 
اللغة هي رموز اجتماعية مشـتركة، أو نظام مناسـب يقدم الأفكار و المثـاعر

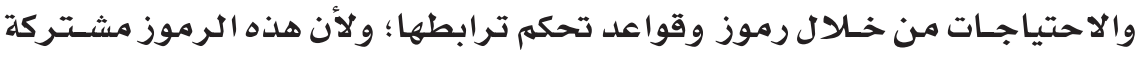

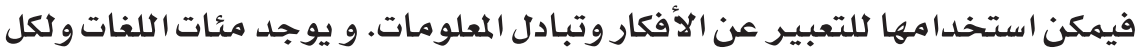

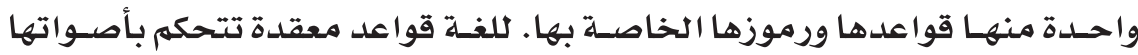

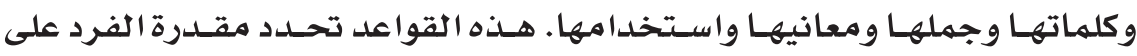

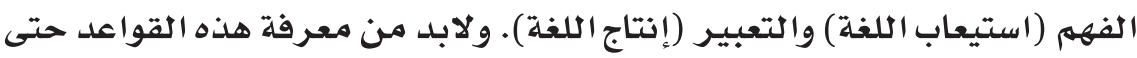

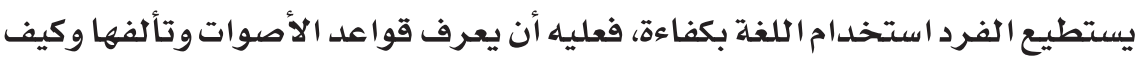

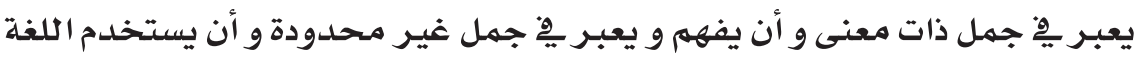

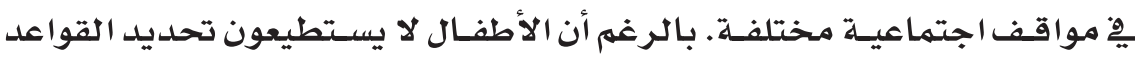

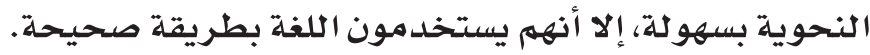

مكونـات اللغة: : تبت

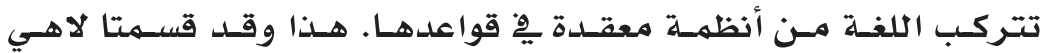

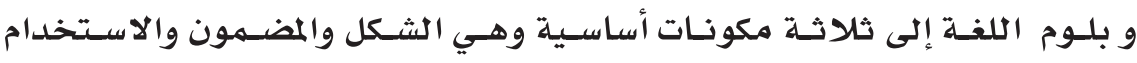
(Lahey \& Bloom, 1978)

$$
\text { أولاً ـ الشكل ( Form ) }
$$

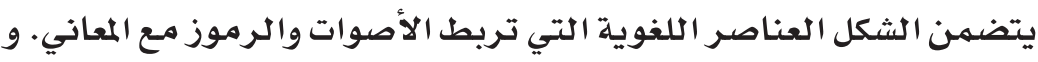

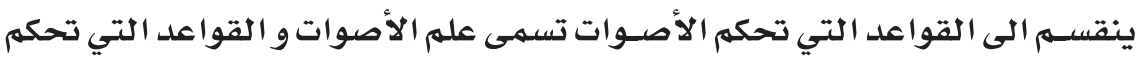

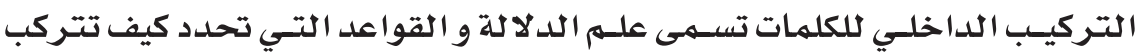
الكلمات بانتظام معلوم لإعطاء جمل تسهى علهم النحو.

أـ علم الأصوات (Phonology)

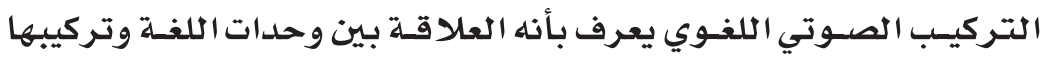

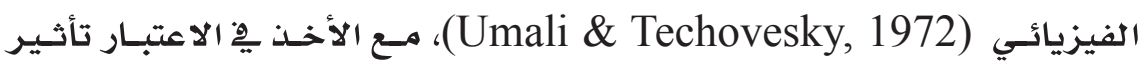
التتابعات الصوتية يٌْ تكوين كلمات اللغة.

الهـوتيات، أو علـم الأصــوات يعـرف بأنه العلاقــة بين الأحســاث الفيزيائية

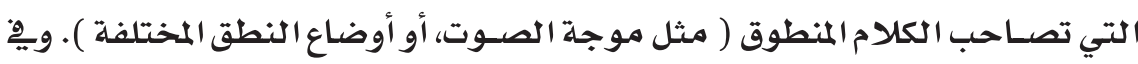


الصـوتيات يتهم دراسـة خصـائص الأصـوات الفيزيائية بلدون الرجوع إلى اللغلة التي تنتهي إليها هذه الأصوات.

و هو النظام الذي يتحكم بالأصوات وتركيبتها. هذا و تتميز كل لغة بأصوات معينـة عن اللغات الأخرى . هذه الوحدات الصـوتية مرتبطة بطرق محلددة لتشـكل وحدات لغوية تعرف بالكلمات.

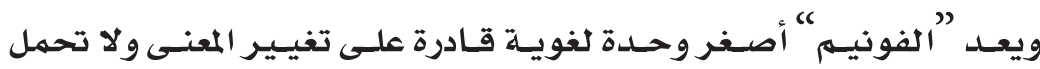

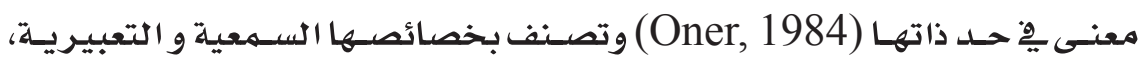
و اسـتخدا مها مـرتبط بهجمهوعتين من القواعد، المجمموعة الأولى تصـف اسـتخدام

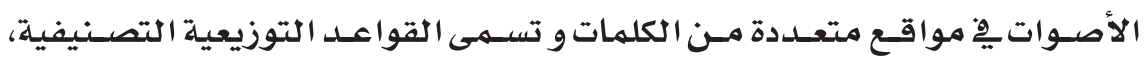
والمجموعة الثانية تحدد الأصوات التي قد تتآلف و تدعى قواعد التتالي. و بهذا فإن القواعد الصوتية تتحكم بالأصوات وتوزيعها وتتاليها ضمن اللغة.

وأمثلـة الفونيمـات /م/ و/ ب/ و/ ل/ / والفونيمـات إذا تغيـر وضعها يف

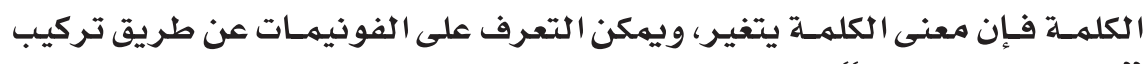

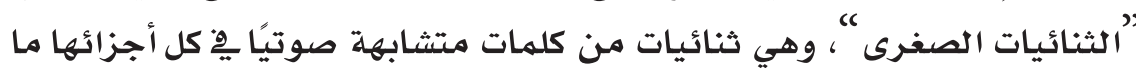

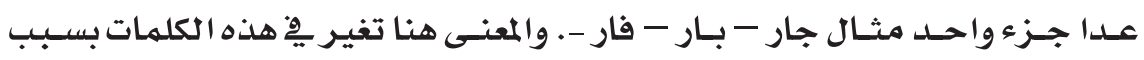
تغير الفونيه.

المقطـع هـو أصــر وحلدة صـوتية إيقاعية للغة ناتجة من دفعـة هواء زفيرية

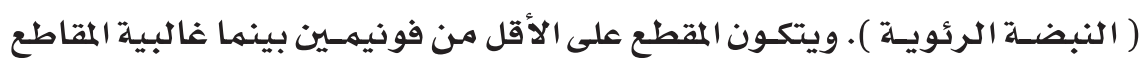
تتكون من ثلاثة فونيمات.

$$
\begin{aligned}
& \text { وينقسه علم التركيب الصوتي اللغوي إلى مستويين: } \\
& \text { المستوي القطعي. } \\
& \text { المستوي فوق القطعي. }
\end{aligned}
$$

المستوي القطعي : يختص بأصوات اللغة التي تنقسه إلى طبقتين أساسيتين وهما السواكن والمتحركات. ولكل من السواكن والمتحركات مهيزاتهما الخاصدة بهما. فالسواكن تنتج من إحداث اختناقات، أو سلدود يِّ طريق هواء الزفير عند الحجرات فوق الحنجرية وهي تمتاز بشدة أقل من المتحركات وتردد أعلى. أمـا المتحركات فتمتاز 
بوجود مهر صـوتي مفتوح وتتكون عن طريق إحداث تغيـراتِفِ شـل واتساع ودرجة

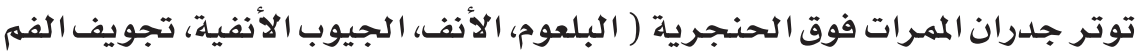

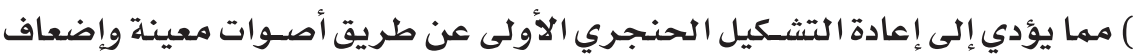

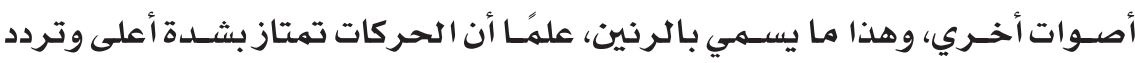
أقل من السواكن (Kotby, 1980) .

المسـتوى فوق القطعي : هو الإطار اللحني ويتكون من نظم المقاطع المختلفة من حيث الشدة والطول والتأكيد. وينتج عن هذا النظم إيقاع لغوي موسيقي مهيز كل لغة بعينها. ورغم أن الإطار اللحني للغة ليس مـرتبطا بفونيم، أو حتى مورفيم

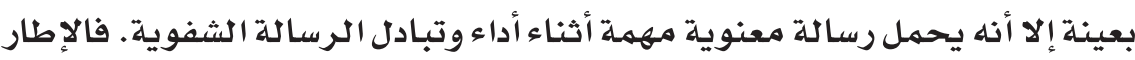
اللحني للغة كثيرًا ما يظهر النواحي العاطفية من فرح وحزن وغضب، بل إنه يحمل نواحي معنوية واضحة مثل الاستفهام والأمر.

والإطـار اللحنـي للغـة يهثل أحسد الأبعـاد المهمهة لرحابـة التركيـب اللغوي. ونقصــد بذلــك أنـه لكي تـرك الرسـالة الشـفوية فليس من الضـروري أن يسـتقبل السـامع ويــرك كل وحلدة صــوتية من اللغة، بل إنه يسـتنتج الكثير منها من خلالال إدراكه للإطار اللحني لتلك الرسالة الشفوية (Kotby, 1987).

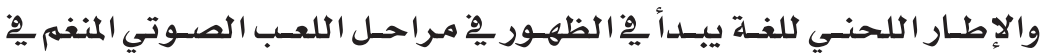
الشهور الأخيرة من السنـة الأولي من العمر . والطفل ِِّ هذه الفترة يكتسب الإطار

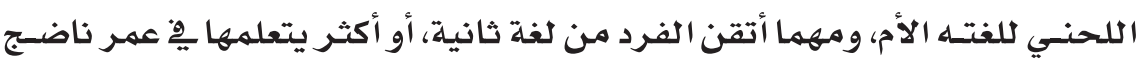

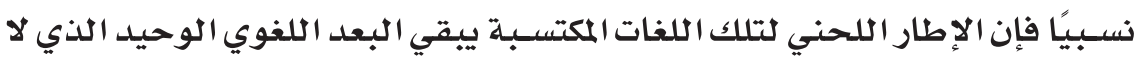
يهكن إتقانه بل والذي منـه يهكن اكتشـاف أن المتحدلث يسـتعمل لغة مكتسبـة و ليست

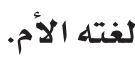

الإطار اللحني يتكون من مجموعة عنـاصر متميزة وفي :

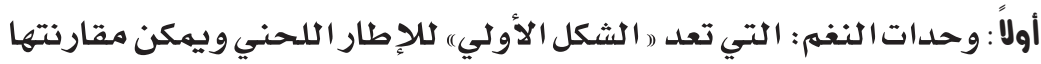
بالجمل يغ التحليل النحوي، وعلي سبيل المثال تقسم الجملة التالية إلى وحدتي نغم

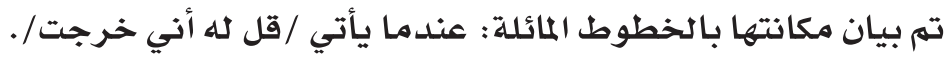




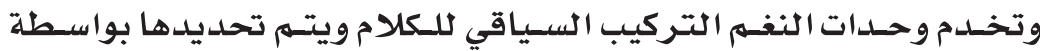

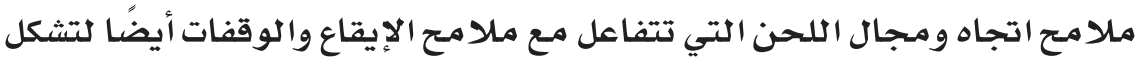

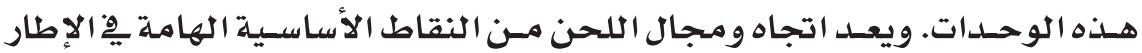

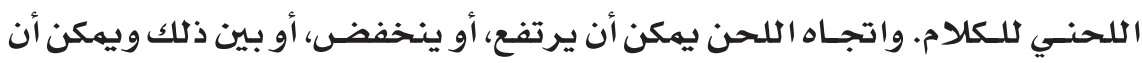
يتسع، أو يضيق بطريقة ما (Krestal, 1975). ثانيًا: التنغيهم: وهو موضــع لأعلى بروز للنغسم مِّم مقطع ما ويتحدد بحركة اللحن والعلو الزائد مـع المدة والوقفات ويهكن بيان المقاطع المنغمة يخِ الجملة الآتية بوضــع خط تحتها: ويرجـح (Polinger, 1972) أن عوامل الدلالة تحدد مواضـع التنغيم مِِ الجملة : لأننا مكثنا في الحفلة حتى منتصف الليل وصلنـا البيت متأخريل. ثالثًا: التضـاد ِِِ النغم: ويوجـد هذا بين المقاطع المختلفـة، فقد يكون اتجاه

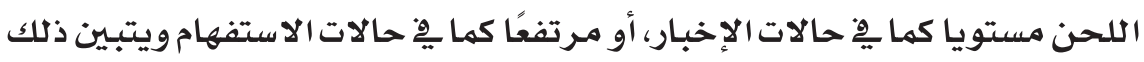

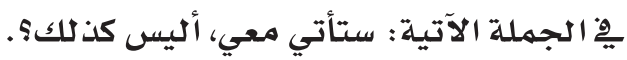

بـ المورفولوجي، أو تركيب الكلدمات، أو الصرف (Morphology):

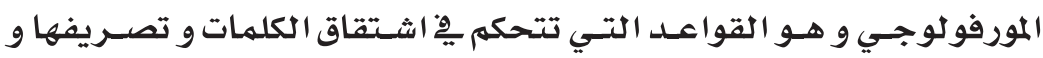

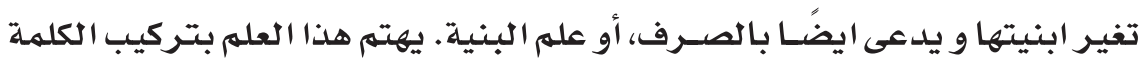
الداخلي وكيف تركب من وحدات تدعى مورفيه، و هي أصغر جزئ لغوي لله معنى و قد تتألف الكلمة من وحدة، أو أكثر .

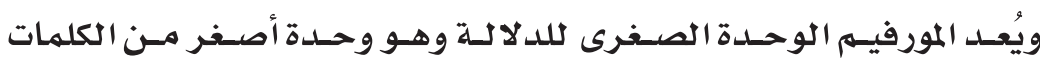

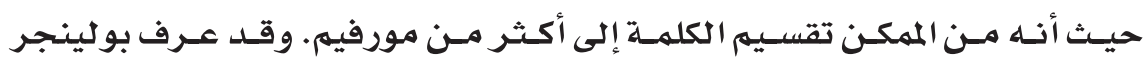
(Polinger, 1965-1975)

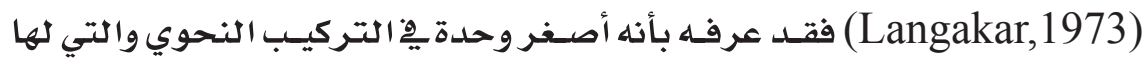

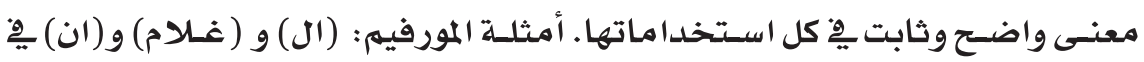

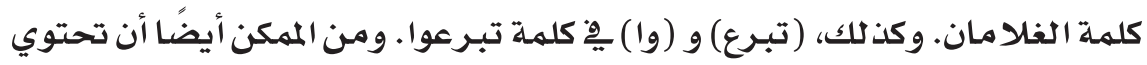

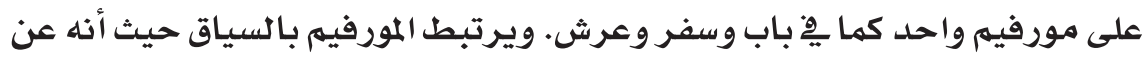
طريـق السـياق يتم مزج وترتيب وتغيير المورفيمات لتوصسيل المعنـى بطريقة معينة .(Moma, 1987) 


\section{أنواع المورفيم: (1) (1)}

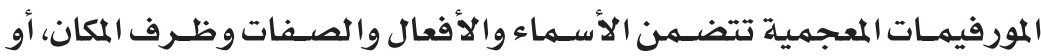

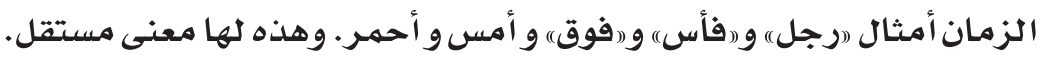

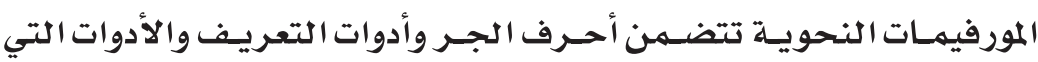

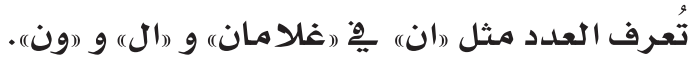

ويمكن تقسيم المورفيمات أيضًا إلى مورفيمات مستقلة ومورفيمات مرتبطة،

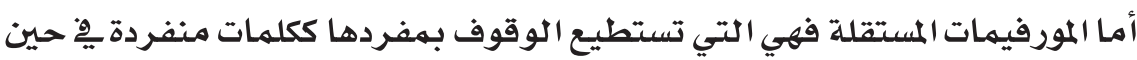

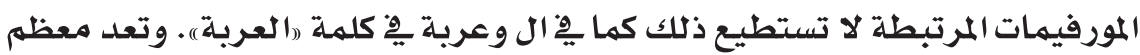

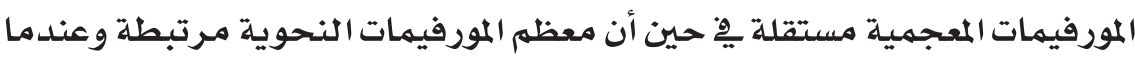

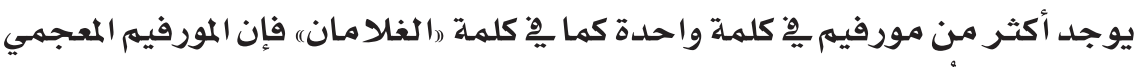

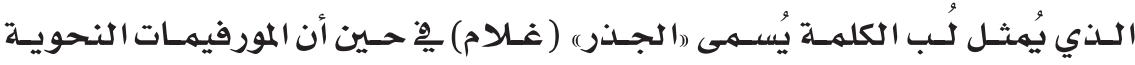

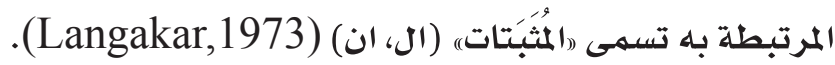

التبديل والاستمداد :

عندما تتصـل المثبتات بالجذر يكون لها آثار مختلفة، هذه الآثار إما أن تكون

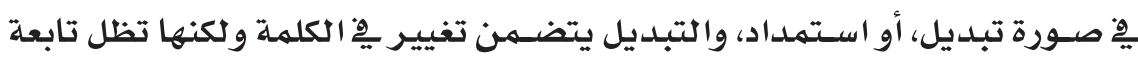

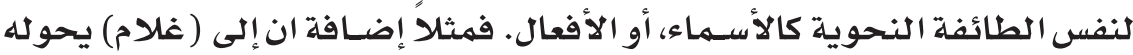

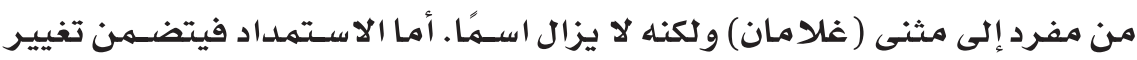

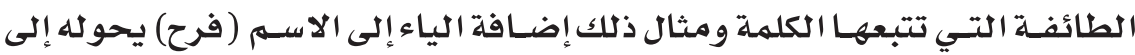

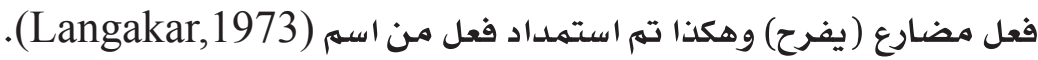

\section{ج- السياق و بنـاء الجملة، أو النـو(Syntax) :}

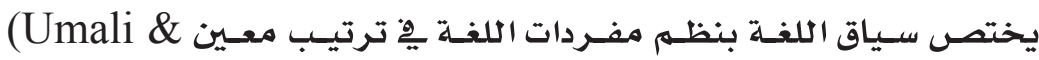

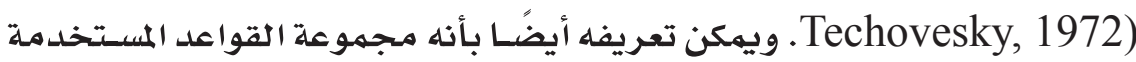

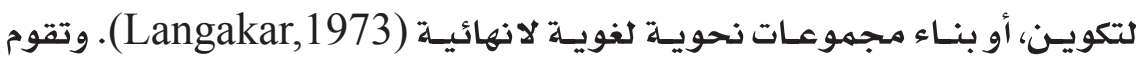
القواعد السياقية بربط التركيبات الإدراكية (العميقة) بالتركيبات السطحية. النحو هو القواعد التي تنظم بناء الجملة و تحدد ترتيب عناصرها وأشكا لها

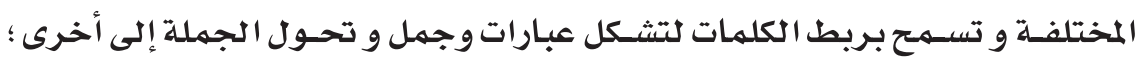

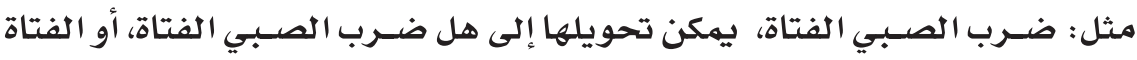


ضـربت من قبل الصبي. إن معرفة هذا القواعد يسمح للفرد بالتعبير بعدد لا متناه

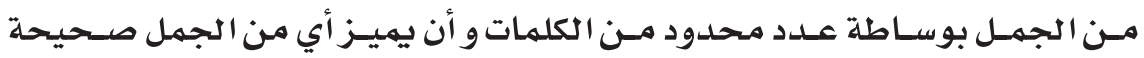

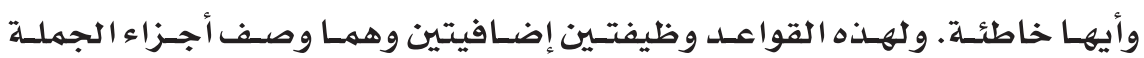
(اسـهم: منـزل) (فهـل: يضـرب) و نوع الجملـة مثل (جملـة اســمية، أو فعليـة) . حالما يبدأ الأطفال بإعطاء جمل أطول فإنهم بهذا يبنون الجمل طبقًا لقواعد التراكيب. فهم يتعلمون كيف يصيغون النفي والأسئلة وجمل الأمر . ولاحقًا يتعلمون استخدام

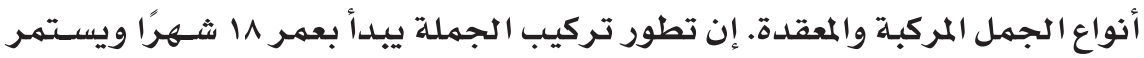
لسنين عديدة.

تحتـوي كل جملـة علـى تركيـب سـطحي وتركيـب عميـق. ويعـرف التركيب السطحي على أنه الشكل، أو الهيئة اللغوية العامـة، وهو يعبـر عن الأفكار الداخلية.

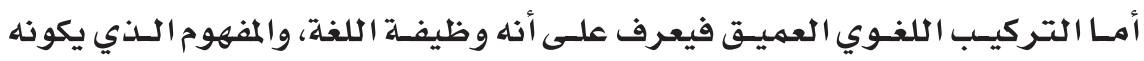
الشـخص ويعبر عنـه بواسـطة التركيب السـطحي. لذلك فإن الشكل اللغوي يخدم الوظيفة اللغوية (Moma, 1978).

والفرق بـين التركيب السـطحي والعميق للغة نسـطيع توضـيحه بواسطة

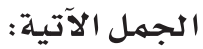

ا. الجمل الملتبسـة وهي جمل لها تركيب سـطحي واحسـ ولكن أكثر من تركيب

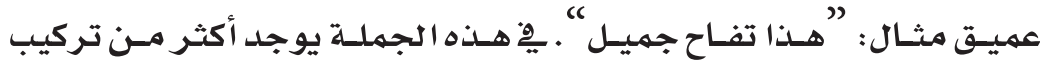
عميق: أحلدهما يشير إلى جمال التفاح والآخر يشير إلى أن هذا التفاح يملكه

جميل.

r. جمل لها تركيب سـطحي متماثل و لكن تركيبات عميقة مختلفة مثل: " "من

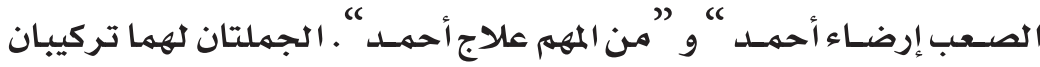
سـطحيان متماثلان تمامًا و كن معانيهـا مختلفة كلية (Moma, 1978).

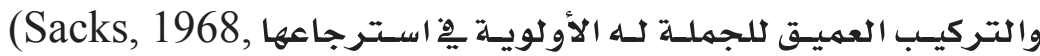

.Slobin, 1974)

وقـلد وضـعت بعضـ النظريـات لتوضـيح التركيـب السـياقي وتعتقـــ بعض النظريات القديمة أنه تركيب بسـيط حيث أن الطفل تســيع إتقانه هِ عمر مبكر، 


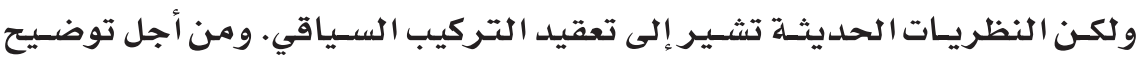

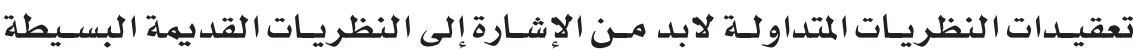

.(Umali \& Techovesky, 1972)

عملية ماركوف:

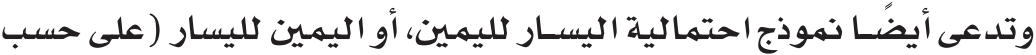

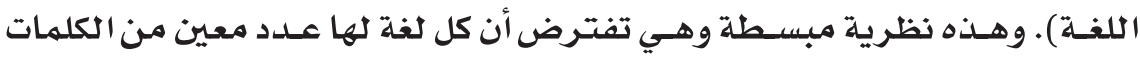

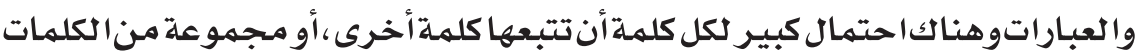
وبهذه الطريقة يتم تكوين سلسلة الكلمات التي يريدها المتحدئماثل (Slobin, 1974).

ومن البديهي أن توجد عدة اعتراضـات على هذه النظرية السـطحية ومنها

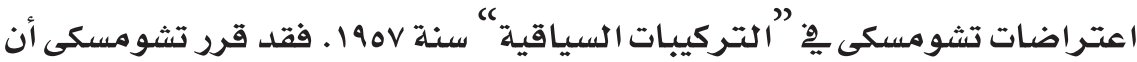

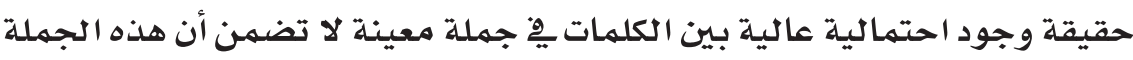

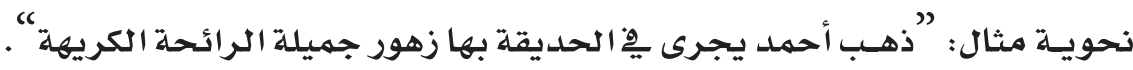

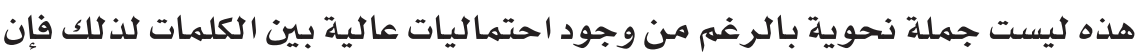
هذه النظرية لا يمكن أن تعبر عن تعقيدات الجمل الرغ الحقيقة.

\section{التركيبة، أو ندو تركيب العبارة:}

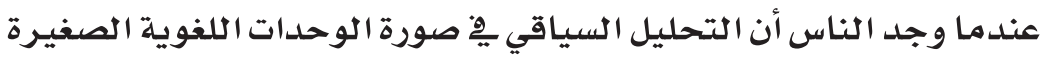

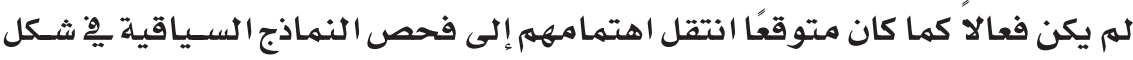

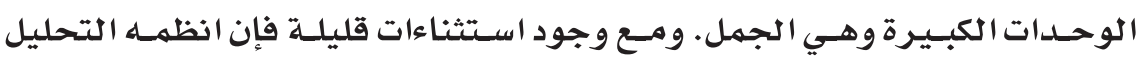

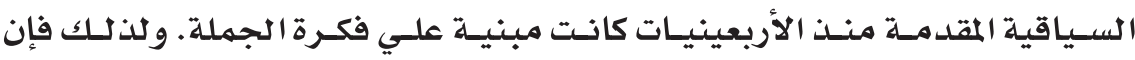

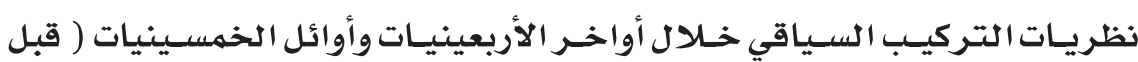
فترة تشومسكي ) كانت مركزة على تحليل تركيب العبارة (Krestal, 1975). تركيـب العبـارة يحــدد التتظيم الأساسـي الخفـي للجملة، فمكونـات الجملة

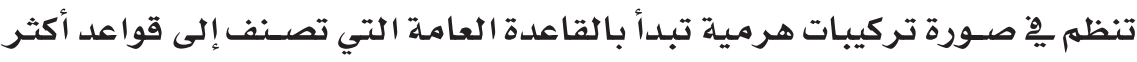

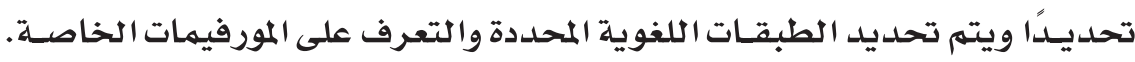

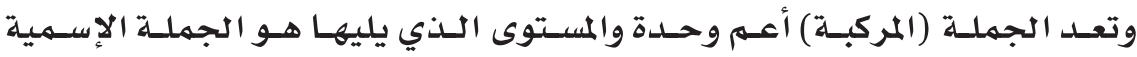

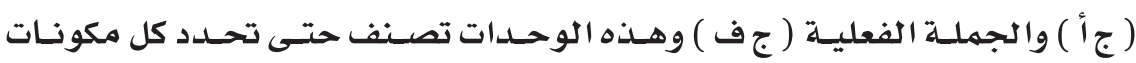

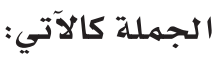




$$
\begin{aligned}
& \text { ج ج ج }
\end{aligned}
$$

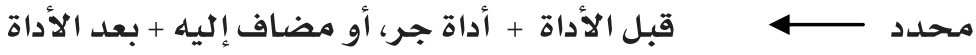

$$
\begin{aligned}
& \text { حيث ج جي أ هي أجملة هي هي }
\end{aligned}
$$

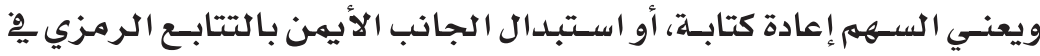

الجانـب الأيسـر ويهكـن إعادة كتابة المحسـد لإظظهار أنه يحتوي قبـل الأداة على زائد أداة تعريف، أو جر، أو اسهم إثارة زائد بعد الأداة بهذا التهابة الترتيب. مثال: كثير من الأولاد العشرة قد نجح يِّا الامتحان.

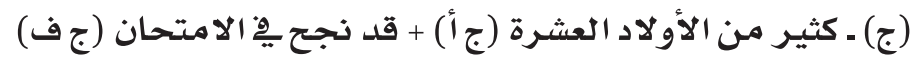
كثير من الأولاد العشرة (ج أ) ـ كثير من العشرة (محسدد) + الأولاد (أ).

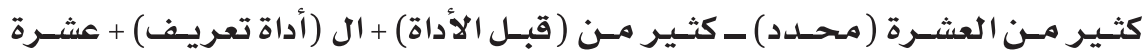

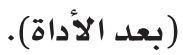

قد نجح ِِ الامتحان (ج ف) ـ قد نجح (ف) + مِّ (أداة جر) + الامتحان (أ). الامتحان (أ) ـ ال ( أداة تعريف) + امتحان (أ). وهكــا فـإن تحليـل الجملة يبدأ برمز ” ج" ويسـتمد كل سـطر من الأســر الـذي يسـبقه عـن طريـق تطبيـق القواعـد المذكـورة أعـلاه، وعندهـا تنتمـي كل

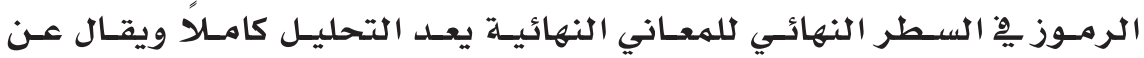

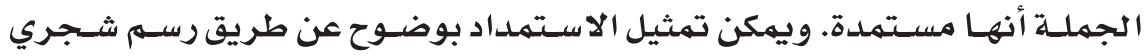
ويبـين هـذا الرسـم الشــري الترتيـب الهرهـي للتركيـب السـطـي للجملـة .(Umali \& Techovesky, 1972) 


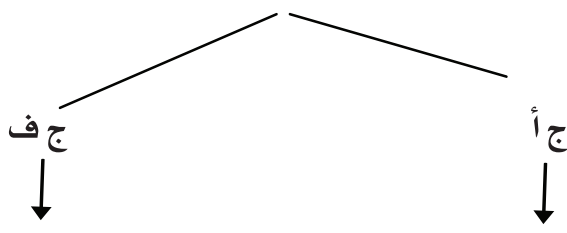

(قبل الأداة) (أداة تعريف + اسهم) (بعد الأداة)... (فعل) (حرف جر) (أداة تعريف + اسم)

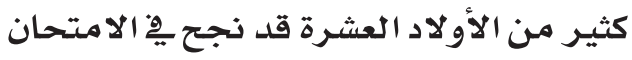

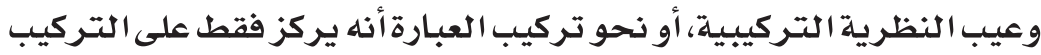

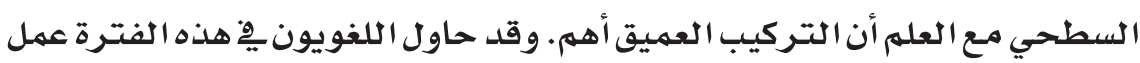

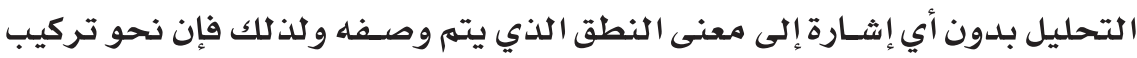

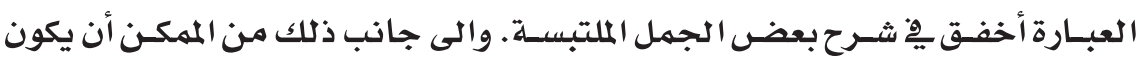

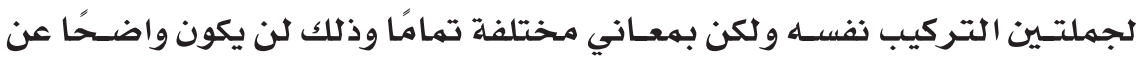

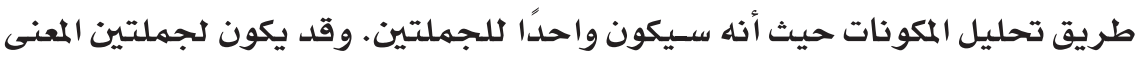

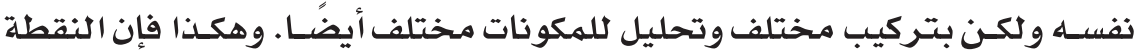

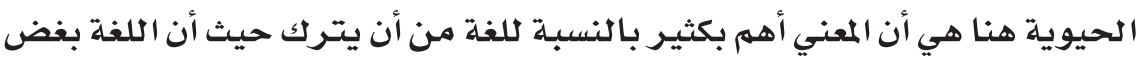

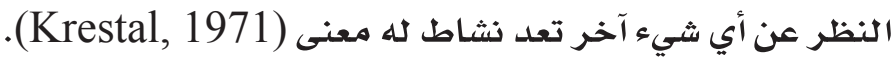

المدظل التمويلي التخليقى : عملت محاو لات كثيرة على خلق تفسير أكثر فمالية للتركيب السياقي وربها

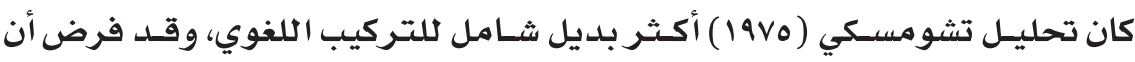

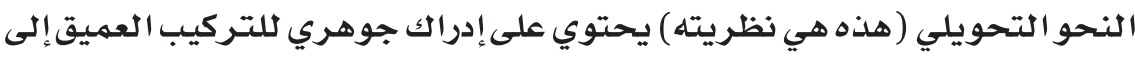
جانب قدرته على معالجة العلاقات التركيبية السطحية أيضًا ( Krestal, 1971).

ويفترضس النمـوذج التحويلي للنحـو وجود تركيب عميق فيـه معنى الجملة

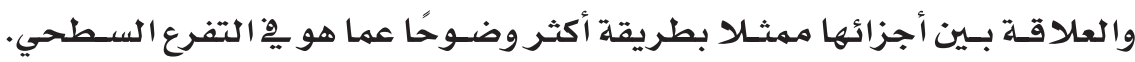

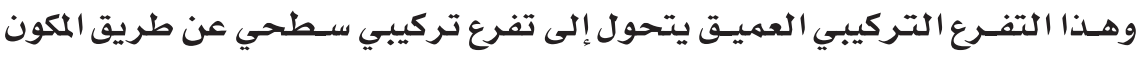

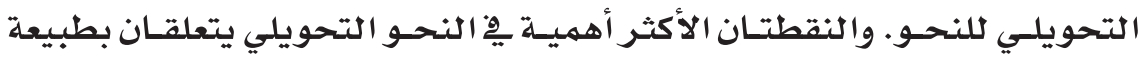

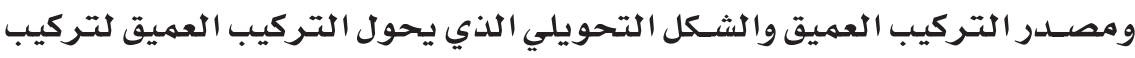
سطحي (Umali \& Techovesky, 1972). 
وتعد الجملة التالية مثالا يوضسح هذه النظرية:

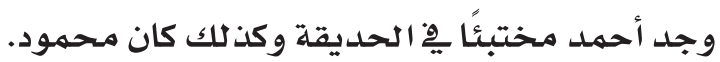
تحتوي هذه الجملة على أربع معلومات رئيسية : ا ـ شخص ما وجد أحمد. r r r شخص ما وجل محسمود.

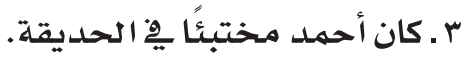

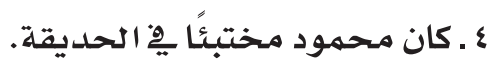

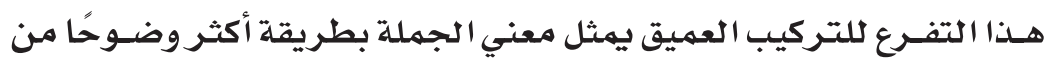
تفـرع التركيب السـطحي، ومـع ذلك فإن تفـرع التركيب العميـق لا يعني التركيب

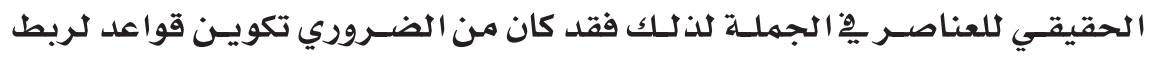
التركيب السـطحي لها وقد سـميت هذه القواعد التي وضـعت بواسـطة تشومسكي

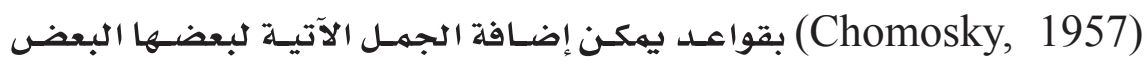

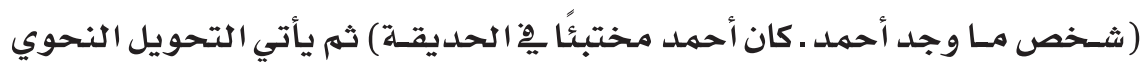
ليلغي عبارة (كان أحمد) ويؤدي إلى الجملة الآتية : (شخص ما وجد أحمد مختبئًا

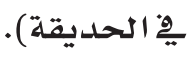

ثـم بعـد ذلك تحول الجملة لمبني للمجههـول (وجد أحمد مختبئًا يِ الحديقة بواسطة شخص ما ) وتلغي عبارة (شخص ما ) بواسطة التحويل النحوي الذي يلغي العناصـر • وبتطبيق نفس التتابع من التحويلات على الجانب الأيسر من التفرعات يهكن إيجاد التركيب الآتي: جملة

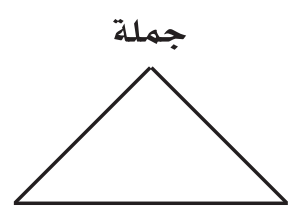

وجد محمود مختبئًا يِ الحديقة

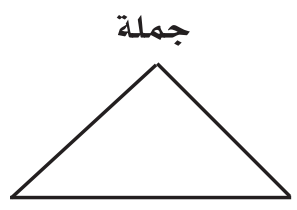

وجد أحمد مختبئًا يِّ الحديقة 


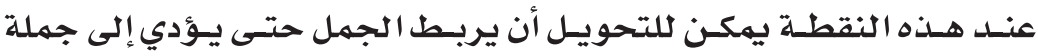

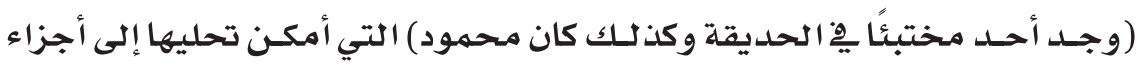
مختلفة بواسطة تفرع تركيب العبارة (Umali \& Techovesky, 1972).

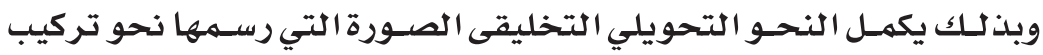

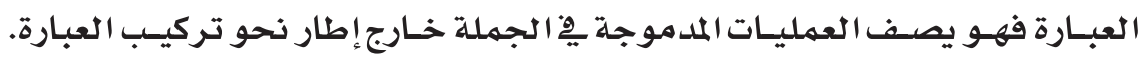

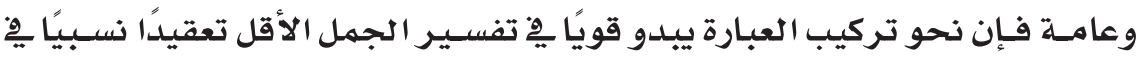

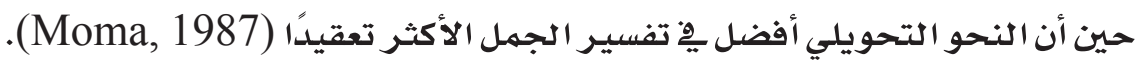

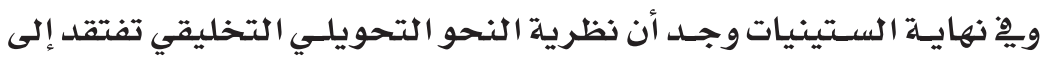

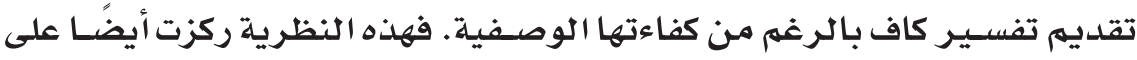

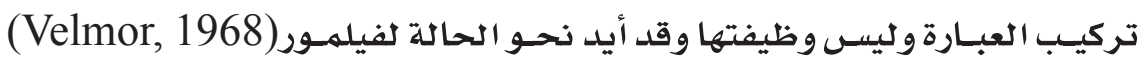
التأكيد على اللغة من وجهة النظة ولنيفر الوظيفية. مدخل فيلمور (Velmor, 1968) لندو الحالة:

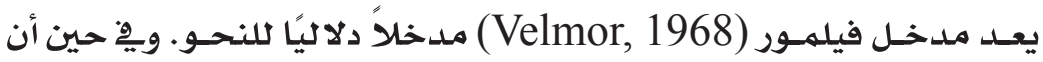

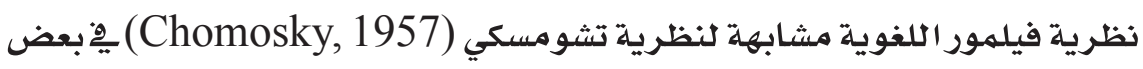

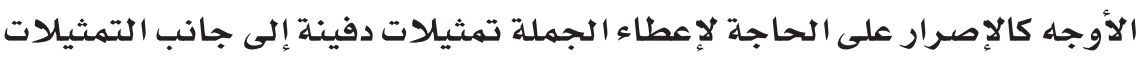

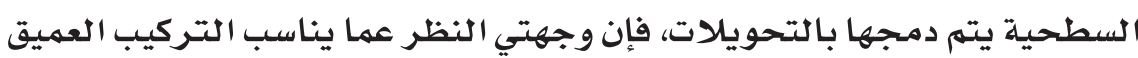

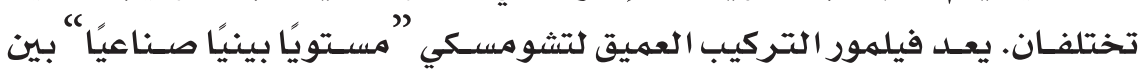
التركيب الد لالي العميق والتركيب السطحي الملموس.

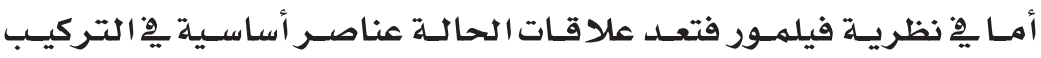

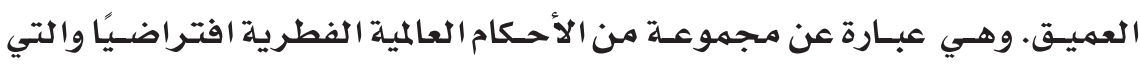

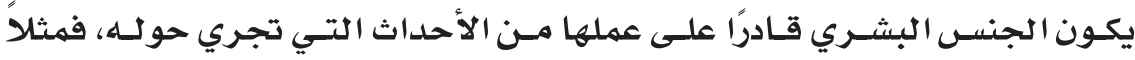

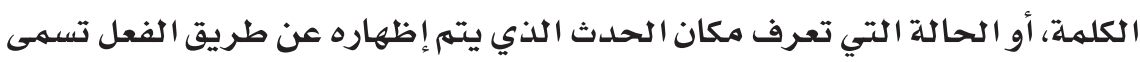

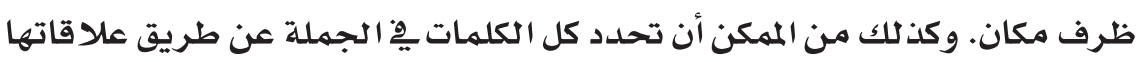

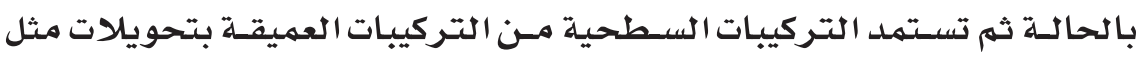

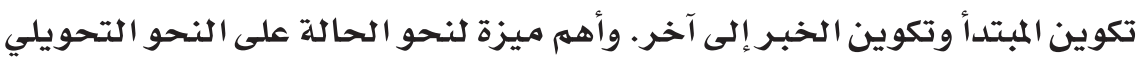

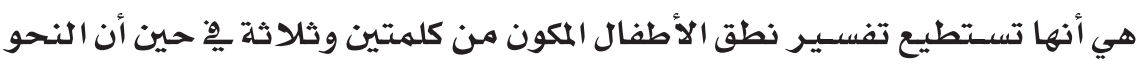


التحويلي لا يستطيع· ومن الصعوبة الشديدة تحليل هذه الألفاظ البسيطة حسب قواعد تركيب العبارة المعقدة (Powerman, 1973).

\section{ثانيًا الدلالة، أو المضمون( Content) :}

يعرف المضمون بأنه معرفة معاني الأشياء والأحداث والأشخاص والعلاوقات. ويقـع تحـت تصــيف علـم المعـاني (Semantic) التعامل مــع الكلهـات ومعانيها. أنـه يشــمل المعـاني التي تحملهـا الكلهات وقاموس المهــطلحات الخاصس بـين المتكلم والمستمع (lexicon). و الأطفال تستخدم الكلمات بشكل مختلف عن البالغين، فقد

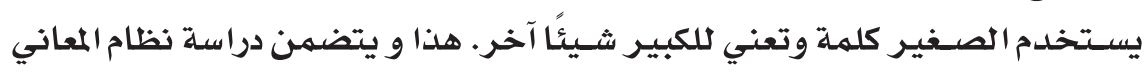
عند الأطفال اختبار فهمهم واستخدامهم للكلمات.

على الرغم أن معاني الكلمات تكون يِّا العادة ظاهرة واضسحة المعنى ويسـهل

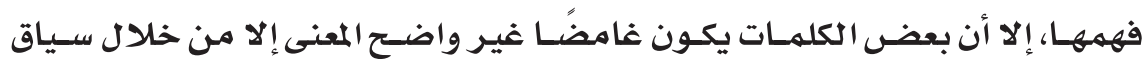
الـكلام مثـل التوريسة. باختصـار فـإن المعـاني تصـل بواسـطة الكلهـات وترابطهـا. فالمضمون يساعد الفرد على معرفة الأثياء والعلاقةات والمفاهيم. تأتي هذه المعرفة من الخبرة وهي نتيجة تطور الاستيعاب عند الفرد.

و تتعلـق الدلالــة بالمعنـى والطريقــة التـي تتعلـق بها الجمل ببعضـها بعضًا وبالعـاله الخارجـي (Umali \& Techovesky, 1972)، بهعنـي أنسه نظـام مكسون مـن قوانين عـدة تحكم معنـى، أو محتـوى الكلهـات، أو مجمهوعـات الكلمات.

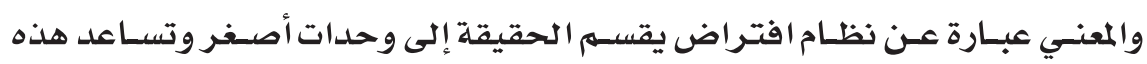

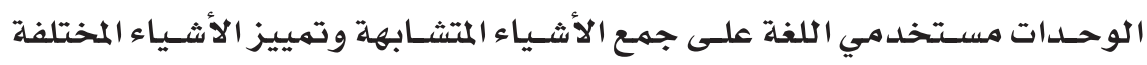
.(Polinger, 1975)

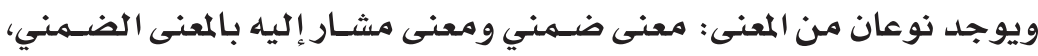

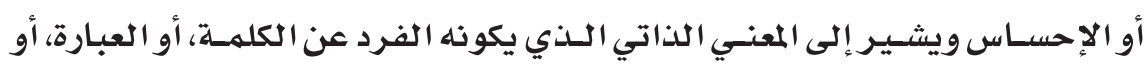

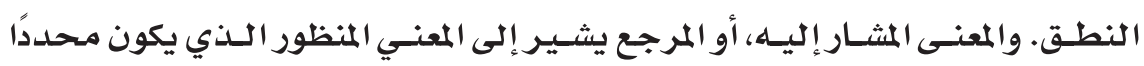
فطريًا بالكلمة (Moma, 1978).

الخـبـرة تســـق المعني فما نعرفـه ونؤمن بـه من التجربة يعسـ ان من مكونات صياغة وفهم اللغة الأولية. ومن هذه الوجهة تعد معاني الكلمات وجهة غير مهمة 


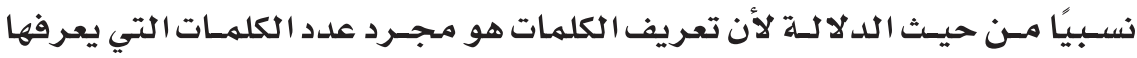

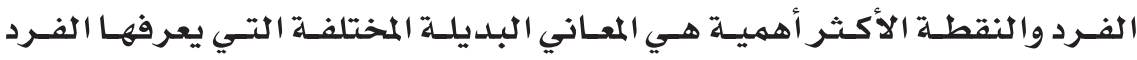

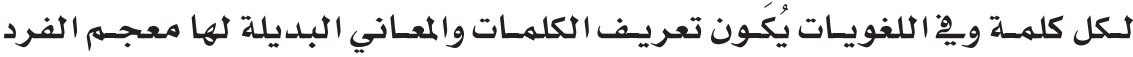

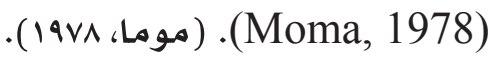

\section{ثالثًا البلاغة، أو استذدام اللغة، أو البرجماتية (Pragmatic/ Use):}

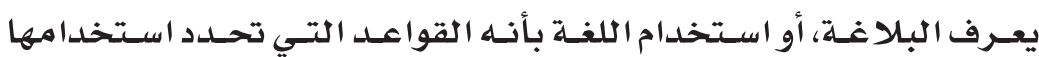

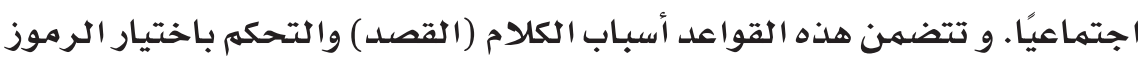

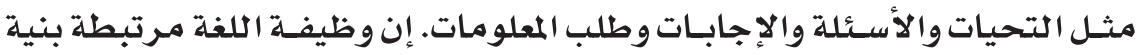

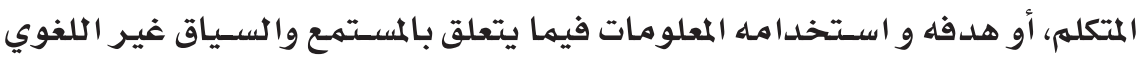

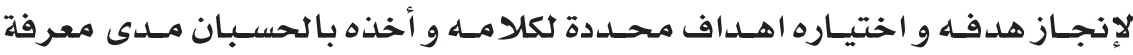

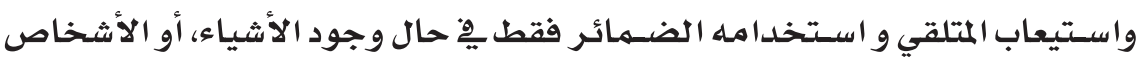

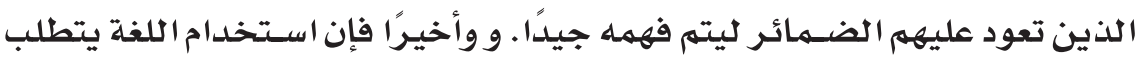

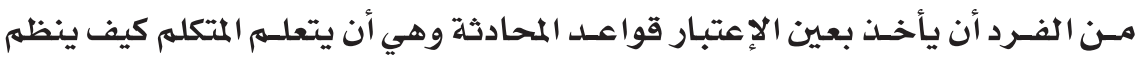

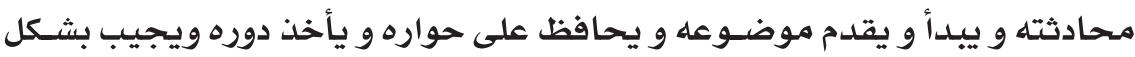

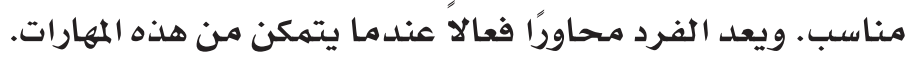

كهـا قـال (Himez, 1972) فِإن فائـدة اللغــة أهـم مـن معرفــة ماهيـة

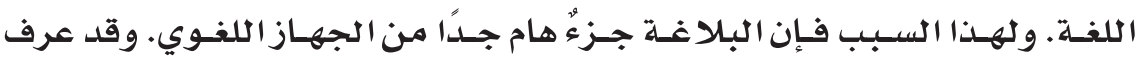

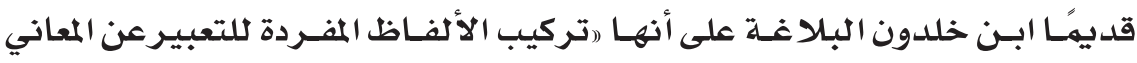

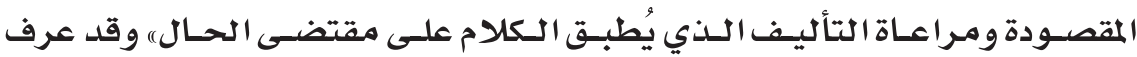

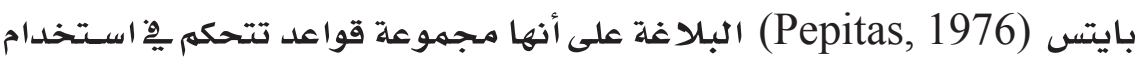

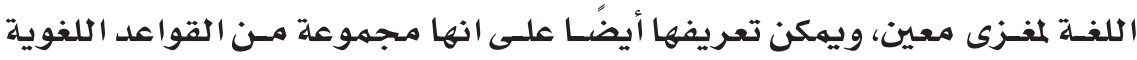

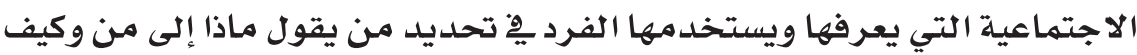
والماذا ومتى ويٌْ أي مواقف (Moma, 1978).

ومن الأهمية فهم المعنى الكامل لكلمة (مغزي) المستخدمة يِّ تعريف بايتس.

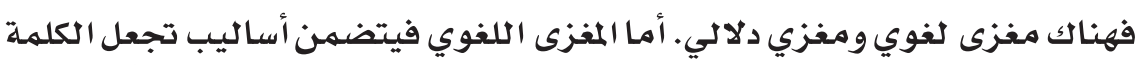

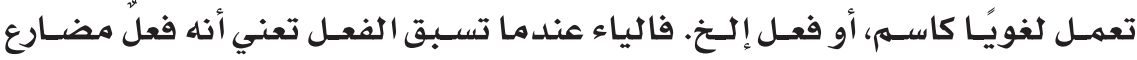

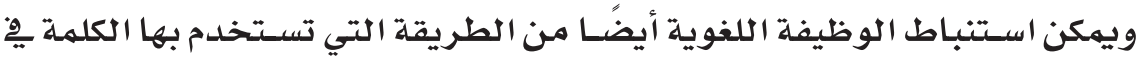


الجمل (Moma, 1978) ففي الجمل الآتية تكون كلمة (فرح) فعل ٍِِ الأولى واسم هِِ الثانية: ه $\quad$ فرح أحمد بنجاحه.

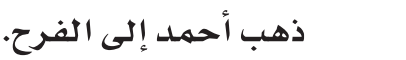

يتضمن المغزى الدلالي الأشياء، أو الناس الذي يشير إليهم المتكلم والطريقة

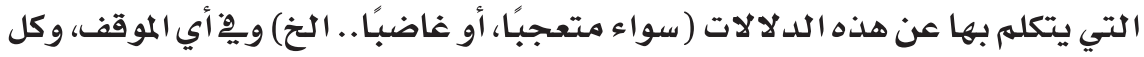

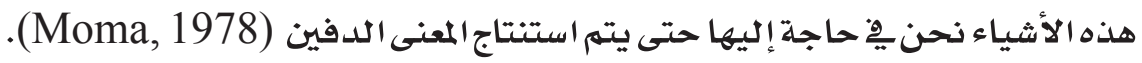

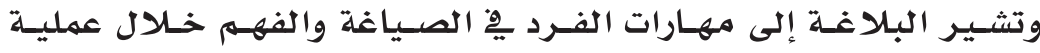

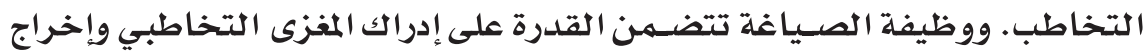

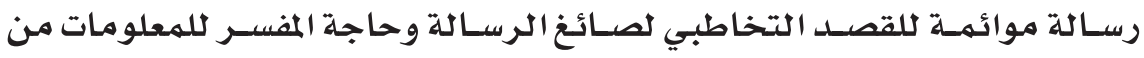

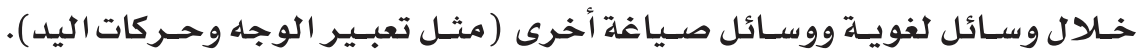

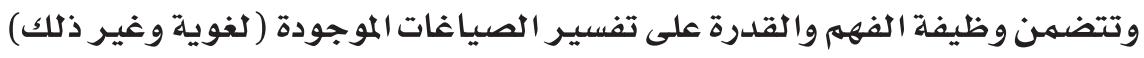

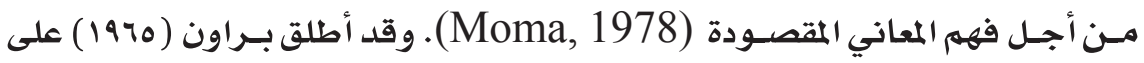

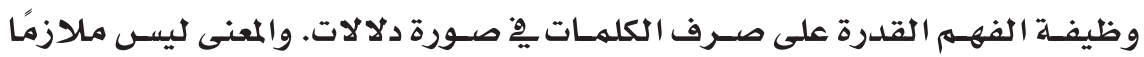

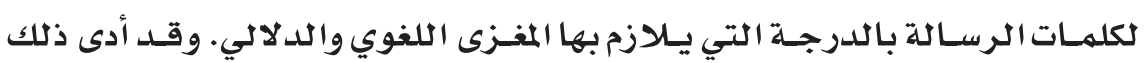

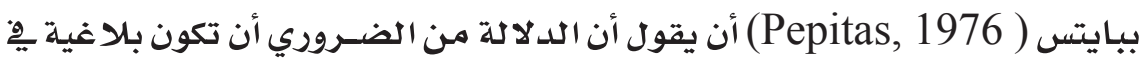

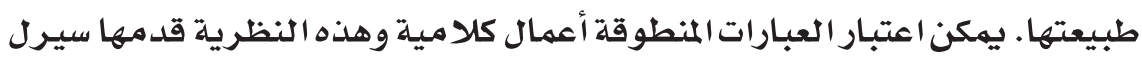

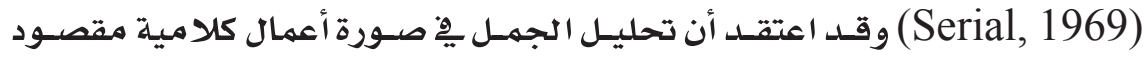

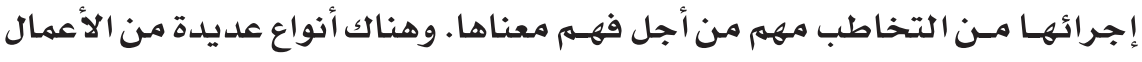

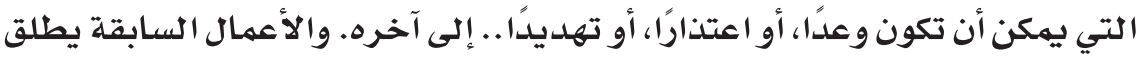

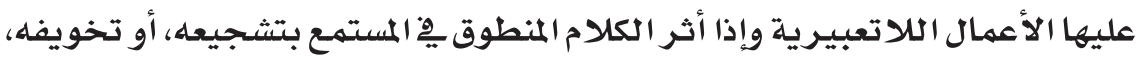

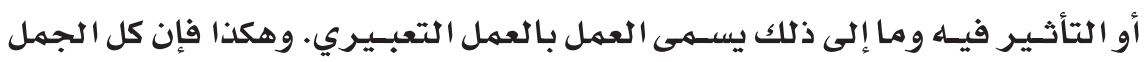
تؤدي أعمالا لا تعبيرية يِّ حين أن بعضها فقط ديؤدي أعمال تعبيرية. ومــن الجائز أن يكون للطفل دراية بالقاعدة المعرفية للغة والأنظمة اللغوية

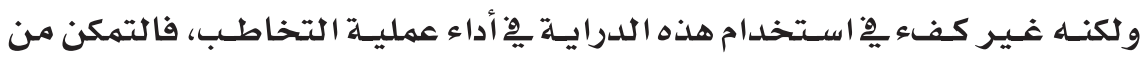
التخاطب يرجع إلى كل من الدراية باللغة واستخدامها (Himez, 1971). 
ومـن الجائز أن يكون للطفل دراية بالقاعدة المعرفية للغة والأنظمة اللغوية

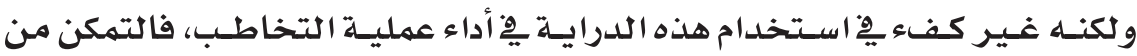

التخاطب يرجع إلى كل من الدراية باللغة واستخدا مه (Himez, 1971).

وعند سـن ^ سـنوات يُقال أن الطفل يفقد الإدراك المُركز على الذات ويصـبح

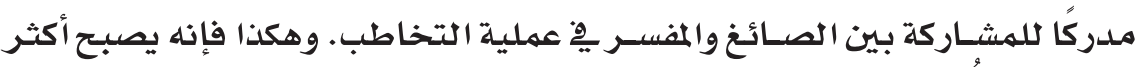
كفاءة. وقد أُطلق على ذلك أسماء عديدة منها أخذ الدور (Falvel et,. al, 1968)

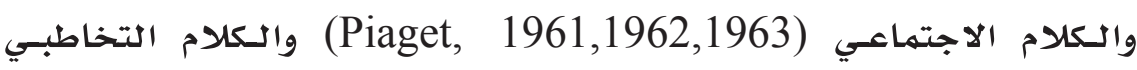
.(Vygotsky, 1979)

طبيعة اللغة معقدة هِّ ذاتها مما يجعل دراسـتها ودراسـة اضطراباتها معقدًا

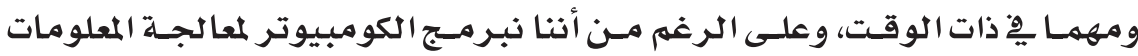

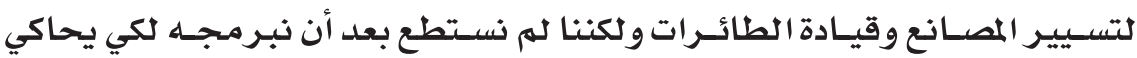

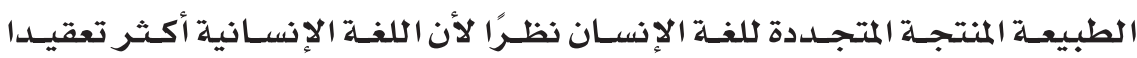

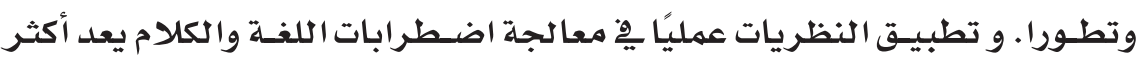

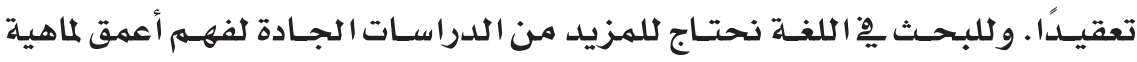
اللغة وطبيعتها واعتلا لاتها. 


\section{المراجع}

حسام منصور (1994). خطط العلاج اللغوي. القاهرة: جامعة عين شمس. عبـــ العزيـز السـرطاوي ووائـل أبـو جـودة (19V0) ). اضطرابـات اللغـة وابـكالام. الرياض: أكاديهية التربية الخاصية.

علي وايِّ (1970) . عله اللغة . القاهرة: دار نهضة مصر.

فيصل الزراد ( •199). اللغة واضطراب النطق والكالام. الرياض: دار المريخ. مـروة صالح (191VV). تأخر نمو اللغة عند الاطفال. القاهرة: جامعة عين شمس. مصطفى فهمي (19V0). أمراض الكلام. القاهرة: مكتبة مصر.

AL Akeel, A. (1998). The acquisition of Arabic language comprehension by Saudi children. Theses, Faculty of Humanities and Social Sciences Newcastle University

Bloom, L. (1988). What is language ?. Lahey, M. (Ed.). Language disorders and language development. New York: Macmillan Publishing Company.

Bernstein, D., \& Tiegerman-Farber, E. (2008). Language and communication disorders in children $\left(6^{\text {th }}\right.$ ed.). New York : Merrill Publishing company.

Chukovsky, K. (1963). From two to five. Berkeley, CA : University of California Press

Cole, K. \& Dale, P. (1986). Direct language instruction and interactive language instruction with language - delayed preschool children: A comparison study. Journal of Speech and Hearing Research, 29, 206- 217.

Dale, P. (1976) Language development: Structure and function. Hinsdale, IL: The Dryden Press

Eimas, P. (1974). Linguistic processing of speech by young infants. In Schiefelbusch, R. Llyod, L. (Eds.). Language perspectives: Acquisition, retardation and intervention. Baltimore: University Park Press. 
Halliday, M. (1975). Learning how to mean. In Lenneberg, E. and Lenneberg, E. (Eds.). Foundations of language development: A Multidisciplinary approach. New York: Academic Press.

Kotby, M.(1980). Diagnosis and management of the communicatively handicapped child. Ain Shams Medical Journal, 31 (3-4) 303317.

Lahey, M. (1988). Language disorders and language development. Macmillan Publishing Company: New York.

Muma , J. (1978). Language handbook by prentice - hall. New Jersey: Inc Englewood cliffs.

Piaget, J. (1963). Psychology of intelligence. New York: Humanities press.

Riper, C., \& Erickson R., ) 1996). Speech correction: An introduction to speech pathology and audiology. Allyn and Bacon: A Simon and Schuster Company, Needlham Heights.

Slobin, D. (1966). Comments on developmental psycholinguistics. In Smith, F. and Miller, G. (Eds.). The genesis of language: A psycholinguistics approach. pp 85-92. Cambridge, Mass. The MIT Press.

Vygostky, L. (1983). School instruction and mental development in Donaldson, M., Grieve, R. and Pratt, C. (Eds.). Early childhood development and education. oxford : Blackwell.

Vygotsky, L. (1978). Mind in society. Cambridge, MA: Harvard university press. 